\title{
Worsened arterial stiffness in high-risk cardiovascular patients with high habitual carbohydrate intake: a cross-sectional vascular function study
}

\author{
Hiu-Ting Chan', Yap-Hang Chan ${ }^{1}$, Kai Hang Yiu', Sheung-Wai Li², Sidney Tam³ ${ }^{3}$ Chu-Pak Lau ${ }^{1}$ and Hung-Fat Tse ${ }^{1 *}$
}

\begin{abstract}
Background: Previous studies suggested that high dietary carbohydrate intake is associated with increased cardiovascular risk through raised triglyceride and decreased high-density lipoprotein-cholesterol levels. However, the relation between carbohydrate intake and arterial stiffness has not been established. The purpose of this study was to examine this relation among high-risk cardiovascular patients.
\end{abstract}

Methods: We studied the relation between dietary macronutrient intake and arterial stiffness in 364 patients with documented cardiovascular diseases or risk equivalent (coronary artery diseases $62 \%$, ischemic stroke 13\%, diabetes mellitus 55\%) and in 93 age-and-sex matched control subjects. Dietary macronutrient intake was assessed using a validated food-frequency questionnaire (FFQ) for Chinese. Heart-ankle pulse wave velocity (PWV) was measured non-invasively with a Vascular Profiling System (VP2000, Colin Corp. USA). A dietary pattern with $\geq 60 \%$ total energy intake derived from carbohydrates was defined as a high-carbohydrate diet according to the Dietary Reference Intakes (DRI) for Chinese.

Results: Subjects who consumed a high-carbohydrate diet had significantly higher mean PWV than those who did not consume a high-carbohydrate diet $(P=0.039)$. After adjustment for potential confounders, high-carbohydrate diet was associated with significantly increased PWV $[B=73.50$ (10.81 to 136.19), $P=0.022]$. However, there was no significant association between high-carbohydrate diet and PWV in controls $(P=0.634)$.

Conclusions: High-carbohydrate diet is associated with increased arterial stiffness in patients with established cardiovascular disease or risk equivalent.

Keywords: Macronutrient, Carbohydrate intake, Arterial stiffness, Pulse wave velocity, Secondary prevention

\section{Background}

Epidemiological studies suggested that dietary macronutrients intake could modify the risk of cardiovascular disease (CVD) [1]. A dietary pattern with high carbohydrate intake from fruits, vegetables, whole grain cereals and low-fat dairy products, but low in saturated fat and total fat, also known as the Dietary Approaches to Stop Hypertension (DASH), has been shown to prevent CVD [2,3]. On the other hand, replacement of carbohydrate with protein or

\footnotetext{
* Correspondence: hftse@hkucc.hku.hk

${ }^{1}$ Division of Cardiology, Department of Medicine, Queen Mary Hospital, the University of Hong Kong, Hong Kong, China

Full list of author information is available at the end of the article
}

unsaturated fat in diet has also been suggested to reduce the risk of CVD [4]. Indeed, a lower percentage of energy intake from carbohydrate was associated with decreased blood pressure, plasma triglyceride and low-density lipoprotein cholesterol (LDL-C), and increased high-density lipoprotein cholesterol (HDL-C) $[1,5,6]$. Conversely, a higher carbohydrate intake may induce hypertriacylglycerolemia [7] In the Optimal Macronutrient Intake Trial to Prevent Heart Disease study, a low carbohydrate diet (partial replacement of carbohydrate with either protein or unsaturated fat) reduced blood pressure, decreased low-density lipoprotein cholesterol and heart disease risk in prehypertensive individuals $[1,6]$. In the Nurses' Health Study, glycemic 
index was associated with lower triacylglycerol among healthy postmenopausal women [8]. In a study of healthy Korean adults, high carbohydrate intake (70\% of energy intake) was associated with higher body-mass index (BMI), blood pressure, fasting glucose, triglycerides and LDL-cholesterol levels [9]. Furthermore, among insulin-resistant and obese persons, excessive intake of energy from carbohydrate $>60 \%$ was associated with unfavorable changes in the lipid profile [6]. Even in patients with non-cardiometabolic chronic diseases, such as women previously treated for breast cancer, high carbohydrate intake was showed to increase fasting level of triacylglycerol [10].

Apart from its effects on the lipid profile, higher carbohydrate consumption also suppresses vascular endothelial function as demonstrated by reduced endotheliumdependent flow-mediated dilation (FMD) [8]. Furthermore, a small pilot study showed that moderate carbohydrate intake can improve arterial stiffness and ambulatory blood pressure [9]. However, whether increased carbohydrate intake may alter atherosclerotic progression in patients with established cardiovascular disease remained unclear. In this study, we sought to investigate the relation between dietary macronutrients intake and arterial stiffness in a group of Chinese subjects with established CVD.

\section{Methods}

\section{Study Populations}

This study comprised 364 consecutive patients with established CVD or risk equivalent, recruited from our outpatient medical clinic. Established CVD included prior coronary artery disease and ischemic stroke, while CVD risk equivalence refers to conditions which confer equivalent cardiovascular risk and in our study context included patients with type II diabetes mellitus but without prior $\mathrm{CAD} /$ ischemic stroke. Inclusion criteria constitute a homogeneous sample of subjects with presence of established coronary disease or factors considered to be of equivalent risks (i.e. ischemic stroke or diabetes mellitus) which place subjects at the medium to advanced spectrum of the cardiovascular continuum [7]. Diagnosis of coronary artery disease was established in the presence of any of the following: a history of myocardial infarction; a history suggestive of angina pectoris objectively evidenced by inducible ischemia on exercise treadmill or SPECT; and the presence of coronary atherosclerosis as defined by coronary angiography, computed tomography or magnetic resonance imaging. Diagnosis of ischemic stroke was made on the basis of clinical examinations and computed tomography brain imaging. Patients with type II DM were defined by WHO criteria [10]. Exclusion criteria constituted presence of non-conventional or non-cardiovascular factors which may present important confounding effects that may result in biased estimates of the relations under study or that may cause temporary potential fluctuations in vascular function parameters. These included dilated cardiomyopathy, pregnancy, history of heart failure, significant valvular heart disease, chronic atrial fibrillation, renal failure (serum creatinine $>1.2 \mathrm{mg} / \mathrm{dL}$ ), cancer, recent myocardial infarction, unstable angina, or coronary revascularization within the past 6 months

During the study period, 93 age- and sex-matched healthy Chinese controls free from history of CVD or diabetes were recruited from a community health screening programme for comparison. The study was approved by the local ethics committee, the Institutional Review Board (IRB) of the University of Hong Kong/ Hospital Authority Hong Kong West Cluster (IRB, HKU/HA HKW Cluster). All participants understood and signed informed consent forms.

\section{Demographic and clinical assessment}

Demographic and clinical data were collected by an interviewer-administered structured questionnaire. Cardiovascular risk factors including tobacco smoking, hypercholesterolemia, hypertension, family history of CVD diagnosed in first-degree relatives before 55 years of age were assessed. Use of cardiovascular medications was recorded. Anthropometric measurements including body weight, height, and waist-hip circumferences ratio were measured. Body mass index (BMI) was then calculated in $\mathrm{kg} / \mathrm{m}$ [2]. Systolic and diastolic blood pressures were measured. Fasting venous blood sample was obtained from all patients to measure serum glucose, HbA1c, triglyceride, total cholesterol, LDL-C and HDL-C levels.

\section{Dietary assessment}

A validated food frequency questionnaire (FFQ) for Chinese were used to assess dietary intake of all subjects over the past 6 months prior to date of interview, as described previously [11-13]. Briefly, subjects were assessed for frequency (day/week/month/year) and amount (unit of intake: liangs, equivalent to $37.8 \mathrm{~g}$ ) intake of particular food past year, and 72 major food groups were recorded in FFQ. Types of fruit assessed included apples, pears, tangerines/oranges/ grapefruits, bananas, grapes, watermelon, peaches and other fruits. Pictures of food with household units were shown to subjects to increase the accuracy of record. The conversion of dietary nutrients was performed by custom-made software as used in the Shanghai Women's health Study [12]. High Carbohydrate diet was defined as daily carbohydrate intake of $\geq 60 \%$ of total energy, i.e. above the daily recommended intake (DRI) of carbohydrate at $60 \%$ of total energy (Chinese Nutrition Society) [14]. 
Table 1 Characteristics of the study population and control subjects

\begin{tabular}{|c|c|c|c|}
\hline & Study population $(n=364)$ & Control $(n=93)$ & $P$-value \\
\hline Characteristics & Mean ( $\pm S D)$ & Mean $( \pm S D)$ & \\
\hline Age (years) & $66.2 \pm 10.2$ & $65.3 \pm 7.1$ & 0.417 \\
\hline Male, $n(\%)$ & $233(64 \%)$ & $49(53 \%)$ & 0.056 \\
\hline BMI (kg/m2) & $24.99 \pm 3.30$ & $23.80 \pm 3.40$ & $0.002^{*}$ \\
\hline Waist-to-hip ratio & $0.93 \pm 0.06$ & $0.91 \pm 0.08$ & $<0.001^{*}$ \\
\hline Ischemic stroke, $n$ (\%) & $49(13.46)$ & - - & $<0.001^{*}$ \\
\hline Coronary artery disease, $n(\%)$ & $224(61.54)$ & - - & $<0.001^{*}$ \\
\hline Diabetes mellitus, $n$ (\%) & $200(54.95)$ & - - & $<0.001^{*}$ \\
\hline Hypertension, $n$ (\%) & $232(63.74)$ & $22(23.66)$ & $<0.001^{*}$ \\
\hline Hyperlipidaemia, $n$ (\%) & $232(63.74)$ & $30(32.26)$ & $<0.001^{*}$ \\
\hline Smokers, $n$ (\%) & $165(45.33)$ & $14(15.05)$ & $<0.001^{*}$ \\
\hline Systolic blood pressure $(\mathrm{mmHg})$ & $141.00 \pm 19.85$ & $127.82 \pm 18.04$ & $<0.001^{*}$ \\
\hline Diastolic blood pressure $(\mathrm{mmHg})$ & $79.16 \pm 9.19$ & $75.06 \pm 9.32$ & $<0.001^{*}$ \\
\hline Total serum cholesterol ( $\mathrm{mmol} / \mathrm{L})$ & $4.50 \pm 0.89$ & $5.12 \pm 0.83$ & $<0.001^{*}$ \\
\hline Serum HDL-C (mmol/L) & $1.28 \pm 0.34$ & $1.48 \pm 0.40$ & $<0.001^{*}$ \\
\hline Serum LDL-C (mmol/L) & $2.56 \pm 0.72$ & $3.05 \pm 0.76$ & $<0.001^{*}$ \\
\hline Serum triacylglycerol (mmol/L) & $1.49 \pm 0.97$ & $1.34 \pm 0.74$ & 0.167 \\
\hline Fasting glucose (mmol/L) & $6.36 \pm 2.07$ & $5.16 \pm 0.60$ & $<0.001^{*}$ \\
\hline $\mathrm{HbA1c}(\%)$ & $7.05 \pm 1.48$ & $6.63 \pm 5.33$ & 0.192 \\
\hline \multicolumn{4}{|l|}{ Medications } \\
\hline Beta-blocker, $n$ (\%) & $184(50.55)$ & $6(6.5)$ & $<0.001^{*}$ \\
\hline ACEI/ARB, $n(\%)$ & $36(9.9)$ & -—- & $<0.001^{*}$ \\
\hline Statin, $n(\%)$ & $226(62.09)$ & $3(3.2)$ & $<0.001^{*}$ \\
\hline $\mathrm{PWV}(\mathrm{cm} / \mathrm{s})$ & $1102.17 \pm 144.54$ & $1079.48 \pm 135.09$ & 0.172 \\
\hline
\end{tabular}

$\mathrm{ACEl}$, angiotensin-converting enzyme inhibitor; ARB, angiotensin receptor blocker; PWV, pulse wave velocity.; HDL-c, high-density lipoprotein cholesterol; LDL-c, low-density lipoprotein cholesterol.

*p-value $<0.05$.

\section{Arterial Stiffness}

Arterial stiffness was measured non-invasively using Vascular Profiling System VP-2000 (Colin Corp., USA). All measurements were performed by a single experienced operator. Patients were allowed to rest in the supine position for 5 minutes in a quiet room before examination. Initially, the sites of maximum carotid and posterior popliteal arteries pulsation were determined by physical examination. Sequential recordings of pressure wave-forms at the precordium and the posterior popliteal arteries were made using hand-held manometer probes with simultaneous electrocardiogram gating. Measurement was taken after achieving coherent reproduction of signals with maximum amplitudes. Heart-ankle pulse wave velocity (PWV) was defined as the distance between the 2 points of measurement over the precordium and the respective posterior popliteal artery, divided by pulse transit time between the systolic R-wave and the upstroke of waveform at the posterior popliteal artery, and was calculated using system software with R-wave synchronisation over at least 10 cardiac cycles. A final estimate was derived from the average of the values from the bilateral measurements. Intra-observer variability testing revealed an intra-class correlation coefficient (two-way mixed, random-effect model, absolute agreement) of 0.87 (95\% CI: 0.80 to $0.91, P<0.001)$ for PWV measurement.

\section{Statistical Methods}

Continuous variables are expressed as mean \pm SDs, and categorical data are presented as frequency and percentages. Statistical comparisons were performed by using Student's $t$ test, Pearson's $X^{2}$ test, or the Fisher's exact test, as appropriate. Absolute changes and 95\% CIs of PWV were calculated by using univariate and multivariate linear regression analysis. Multivariate analyses were performed such that potentially confounding variables and known variables involved in prediction of PWV were chosen, including use of antihypertensive medications and statin $[15,16]$. Each independent variable was considered a potential confounder if the p-value was $<0.20$ based on univariate analysis, and 
was entered and adjusted for in the multivariate Model. Multivariate linear regression analysis was repeated using the overall sample including all subjects, as well as separately among patients with CVD risk equivalent versus healthy controls. In the Full Model, all independent variables were entered and adjusted for all (Table 1). All data analyses were performed using the Statistical Package for the Social Sciences (version 16.0, SPSS). A value of P value less than 0.05 was considered statistically significant.

\section{Results}

\section{Baseline characteristics}

The baseline characteristics of the study population were shown in Table 1 . Their mean age was $66.2 \pm 10.2$ years and $64 \%$ of the participants were men. Among them, $62 \%$ had documented coronary artery disease, $55 \%$ had type II diabetes mellitus and13\% had ischemic stroke. Among them, $64 \%$ of patients had hypertension and $64 \%$ had hyperlipidaemia. And $45 \%$ of patients were smokers.

The daily dietary profiles of the study population as measured by FFQ were presented in Table 2. The percentage of energy intake derived from carbohydrate, protein and fat were $72.3 \pm 7.6 \%, 15.2 \pm 2.9 \%$ and $12.5 \pm 5.4 \%$, respectively. Energy intake was significantly reduced among cases compared to controls $(P<0.001)$, with different pattern of intake of major food groups.

\section{Effects of dietary high carbohydrate diet on blood pressure and lipid profile}

As shown in Table 3, high carbohydrate diet was significantly associated with increased systolic blood pressure $[\mathrm{B}=2.86,95 \% \mathrm{CI}(1.96$ to 3.76$), P<0.001]$, adjusted for age and sex. However, no significant differences were seen in subjects with high carbohydrate diet in terms of diastolic blood pressure, serum LDL-c, HDL-c, and triacylglycerol $(P>0.05)$.

\section{Effects of high carbohydrate diet on pulse wave velocity}

In univariate analysis, high-carbohydrate diet was associated with significantly increased PWV among patients with CVD risk equivalent $[\mathrm{B}=72.21,95 \% \mathrm{CI}$ (3.80 to 140.62), $P=0.039]$. Similar association was found among the overall study sample $(\mathrm{n}=457)$ with marginal statistical significance $[\mathrm{B}=50.52,95 \% \mathrm{CI}(-6.03$ to 107.07$), P=0.080$ ]. Adjusted for potential confounders (including age, sex, diabetes mellitus, smokers, hypertension, hyperlipidaemia, cardiovascular diseases, BMI, and use of medications, including beta-blocker, angiotensin-converting enzyme inhibitor/ angiotensin receptor blocker and statins), dietary energy intake, saturated fat, polyunsaturated fat, monounsaturated fat, fiber, high-carbohydrate diet remained independently associated with PWV $[\mathrm{B}=73.50$ (10.81 to 136.19), $P=0.022$, Table 4]. Repeated analysis using Full

Table 2 Dietary profile of the study population and control subjects

\begin{tabular}{|c|c|c|c|}
\hline & Study population $(n=364)$ & Control subjects $(n=93)$ & P-value \\
\hline Characteristics & Mean $( \pm S D)$ & Mean $( \pm S D)$ & \\
\hline Energy intake/day (Kcal/d) & $1978.22 \pm 725.57$ & $2393.10 \pm 836.76$ & $<0.001^{*}$ \\
\hline Carbohydrate (g/d) & $359.85 \pm 145.80$ & $436.88 \pm 168.39$ & $<0.001^{*}$ \\
\hline High carbohydrate diet $(\geqq 60 \%)(n, \%)$ & $346(95.05)$ & $85(91.40)$ & 0.207 \\
\hline Protein $(g / d)$ & $73.95 \pm 27.43$ & $87.06 \pm 35.26$ & $<0.001^{*}$ \\
\hline Fat $(g / d)$ & $26.97 \pm 15.48$ & $32.98 \pm 17.70$ & $0.001^{*}$ \\
\hline Carbohydrate (\% of energy ) & $72.32 \pm 7.62$ & $72.54 \pm 8.80$ & 0.807 \\
\hline Protein (\% of energy ) & $15.21 \pm 2.94$ & $14.81 \pm 3.68$ & 0.271 \\
\hline Fat (\% of energy ) & $12.46 \pm 5.39$ & $12.63 \pm 5.76$ & 0.794 \\
\hline Rice & $451.63 \pm 191.80$ & $539.36 \pm 221.40$ & $<0.001^{*}$ \\
\hline Vegetables & $132.78 \pm 98.82$ & $161.07 \pm 109.71$ & $0.016^{*}$ \\
\hline Meat & $61.41 \pm 58.41$ & $79.25 \pm 112.54$ & $0.035^{*}$ \\
\hline Poultry & $19.09 \pm 20.85$ & $23.85 \pm 25.77$ & 0.062 \\
\hline Fish & $68.23 \pm 70.13$ & $63.56 \pm 53.48$ & 0.549 \\
\hline Egg & $9.25 \pm 12.72$ & $9.50 \pm 11.00$ & 0.864 \\
\hline Fruit & $53.95 \pm 40.80$ & $70.13 \pm 48.98$ & $0.001^{*}$ \\
\hline Soy & $32.79 \pm 45.75$ & $49.80 \pm 71.00$ & $0.005^{*}$ \\
\hline Fiber & $9.26 \pm 6.33$ & $10.63 \pm 4.72$ & 0.051 \\
\hline Saturated fat & $7.00 \pm 4.72$ & $9.08 \pm 6.43$ & $<0.001^{*}$ \\
\hline Polyunsaturated fatty acids & $5.06 \pm 2.63$ & $6.15 \pm 3.51$ & $0.002^{*}$ \\
\hline
\end{tabular}

${ }^{*} P<0.05$ Significantly different from high carbohydrate diet and without high carbohydrate diet (independent sample $t$-test). 
Table 3 Effects of high-carbohydrate diet on blood pressure and serum lipid profile ${ }^{a}$

\begin{tabular}{|c|c|c|}
\hline & $B(95 \% \mathrm{Cl})$ & $\begin{array}{l}\text { Adjusted } \\
p \text {-value }\end{array}$ \\
\hline \multicolumn{3}{|l|}{ Systolic blood pressure $(\mathrm{mmHg})$} \\
\hline \multicolumn{3}{|l|}{$\begin{array}{l}\text { Without high carbohydrate } \\
\text { diet }(<60 \%)\end{array}$} \\
\hline High carbohydrate diet ( $\geqq 60 \%)$ & 2.86 (1.96 to 3.76$)$ & $<0.001^{*}$ \\
\hline \multicolumn{3}{|l|}{ Diastolic blood pressure $(\mathrm{mmHg})$} \\
\hline \multicolumn{3}{|l|}{$\begin{array}{l}\text { Without high carbohydrate } \\
\text { diet }(<60 \%)\end{array}$} \\
\hline High carbohydrate ( $\geqq 60 \%)$ & 0.68 (-1.26 to 2.62$)$ & 0.491 \\
\hline \multicolumn{3}{|l|}{ Total cholesterol (mmol/L) } \\
\hline \multicolumn{3}{|l|}{$\begin{array}{l}\text { Without high carbohydrate } \\
\text { diet }(<60 \%)\end{array}$} \\
\hline High carbohydrate ( $\geqq 60 \%)$ & $23.57(-38.98$ to 86.11$)$ & 0.459 \\
\hline \multicolumn{3}{|l|}{ HDL cholesterol (mmol/L) } \\
\hline \multicolumn{3}{|l|}{$\begin{array}{l}\text { Without high carbohydrate } \\
\text { diet }(<60 \%)\end{array}$} \\
\hline High carbohydrate ( $\geqq 60 \%)$ & $-38.96(-109.85$ to 31.93$)$ & 0.280 \\
\hline \multicolumn{3}{|l|}{ LDL cholesterol (mmol/L) } \\
\hline \multicolumn{3}{|l|}{$\begin{array}{l}\text { Without high carbohydrate } \\
\text { diet }(<60 \%)\end{array}$} \\
\hline High carbohydrate ( $\geqq 60 \%)$ & $-8.75(-75.29$ to 57.80$)$ & 0.796 \\
\hline \multicolumn{3}{|l|}{ Triacylglycerol (mmol/L) } \\
\hline \multicolumn{3}{|l|}{$\begin{array}{l}\text { Without high carbohydrate } \\
\text { diet }(<60 \%)\end{array}$} \\
\hline High carbohydrate ( $\geqq 60 \%)$ & $-2.80(-28.87$ to 23.27$)$ & 0.833 \\
\hline
\end{tabular}

${ }^{a}$ Adjusted for age and sex.

*p-value $<0.05$.

Model yielded similar results $[\mathrm{B}=231.39,95 \% \mathrm{CI}$ (87.19 to 375.58), $P=0.003]$. Nevertheless, no significant association was observed between carbohydrate intake and PWV in healthy controls $[\mathrm{B}=-28.52,95 \% \mathrm{CI}(-147.83$ to 90.80$)$, $\mathrm{P}=0.634$, Table 4].

\section{Discussion}

High-carbohydrate diet is associated with increased cardiovascular risk [17-19], in terms of adverse changes in cardiovascular risk factors, such as raised serum triglycerides and reduced levels of high-density lipoprotein cholesterol, but its relation with vascular function remained unclear. In coherence with an earlier small pilot study showing that moderate carbohydrate diet reduced PWV [9], this study further shows that high-carbohydrate diet is independently associated with increased PWV in patients with established cardiovascular disease or risk equivalent. Arterial stiffness as measured by PWV has been shown to be an important clinical marker of atherosclerosis [20,21], and is a predictor of cardiovascular events in healthy subjects beyond traditional risk factors
[22]. The results of this study suggest that increased carbohydrate intake in patients with established cardiovascular disease or risk equivalent may potentially contribute to further increased risk of future cardiovascular events through accelerated progression of atherosclerosis. The mechanisms linking arterial stiffness to CVD are not completely understood, and may involve insulin resistance promoting endothelial dysfunction, oxidative stress, vascular smooth muscle cell growth and stimulation of the sympathetic nervous system [23].

There are several possible mechanistic pathways through which high-carbohydrate diet could impact on atherosclerosis, and these included changes in blood pressure, lipid profile, or modulation of inflammatory cytokines and the nitric oxide system [24,25]. In this study, increased carbohydrate intake is associated with raised systolic blood pressure, which is consistent with the previous finding of beneficial changes in ambulatory blood pressure associated with a low glycemic index diet [9]. No changes were observed in glycemic and lipid profiles in this study in relation to a high carbohydrate diet. These findings suggest that high-carbohydrate diet may affect arterial stiffness through altering BP but not lipid profile.

Notably, the percentage of smokers among patients with established cardiovascular diseases was markedly higher than that among control subjects $(45.3 \%$ versus $15.1 \%, P<0.001)$. The adverse effects of cigarette smoke in atherogenesis are indispensible, mediated by multiple pathways including free radical-induced oxidative stress as well as pro-thrombotic and pro-inflammatory cascades [26]. We therefore carefully adjusted for the effects of smoking in the multivariate analysis, and showed that the pro-atherosclerotic effects of high carbohydrate diet were independent of smoking. Interestingly, the pro-atherosclerotic effect of high carbohydrate diet was present in patients with cardiovascular disease or risk equivalent, but not in healthy control subjects. This suggests that high carbohydrate diet may preferentially affect the most susceptible patients at the advanced spectrum of the cardiovascular continuum. This implies that dietary interventions [27] to reduce habitual carbohydrate intake may have an important role in secondary prevention of cardiovascular disease.

\section{Study limitations}

First, the glycemic index was not determined in this study, therefore direct comparison with previous studies could be difficult and the specific type of carbohydrate cannot be ascertained. Second, a direct causality of dietary carbohydrate intake and arterial stiffness cannot be established in a cross-sectional setting. Furthermore, the method in measuring heart-ankle PWV was not a priori 
Table 4 Unadjusted and adjusted relations of high carbohydrate intake with PWV in study population and control subjects

\begin{tabular}{|c|c|c|c|c|c|c|c|c|}
\hline & \multirow{2}{*}{\multicolumn{2}{|c|}{$\begin{array}{c}\text { Univariate model } \\
\begin{array}{c}\text { All subjects included } \\
(n=457)\end{array}\end{array}$}} & \multicolumn{6}{|c|}{ 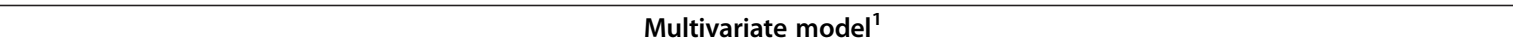 } \\
\hline & & & \multicolumn{2}{|c|}{$\begin{array}{l}\text { All subjects included } \\
\quad(n=457)\end{array}$} & \multicolumn{2}{|l|}{$\begin{array}{l}C V D / \text { risk equivalent } \\
(n=364)\end{array}$} & \multicolumn{2}{|l|}{$\begin{array}{l}\text { Healthy controls } \\
\quad(n=93)\end{array}$} \\
\hline & $\beta(95 \% \mathrm{Cl})$ & $\overline{p \text {-value }}$ & $\beta(95 \% \mathrm{Cl})$ & $\overline{p \text {-value }}$ & $\beta(95 \% \mathrm{Cl})$ & $p$-value & $\beta(95 \% \mathrm{Cl})$ & $\overline{p \text {-value }}$ \\
\hline Age & 6.61 (5.39 to 7.83 ) & $<0.001^{*}$ & 6.68 (5.42 to 7.94$)$ & $<0.001^{*}$ & 6.27 (4.93 to 7.61$)$ & $<0.001^{*}$ & 9.88 (5.77 to 13.99) & $<0.001^{*}$ \\
\hline Male & $28.08(1.17$ to 55.00$)$ & 0.041 & 33.38 (8.40 to 58.36$)$ & $0.009^{*}$ & $23.55(-4.46$ to 51.56$)$ & 0.099 & 67.87 (10.17 to 125.58$)$ & $0.022^{*}$ \\
\hline Diabetes mellitus & 18.81 (-8.19 to 45.80$)$ & 0.172 & 46.34 (18.93 to 73.76$)$ & $0.001^{*}$ & 43.18 (15.22 to 71.14$)$ & $0.003^{*}$ & $150.75(-88.20$ to 389.71$)$ & 0.212 \\
\hline Hypertension & 69.97 (44.07 to 95.87$)$ & $<0.001^{*}$ & 53.52 (27.82 to 79.21$)$ & $<0.001^{*}$ & 58.61 (30.39 to 86.83) & $<0.001^{*}$ & $22.69(-45.87$ to 91.25$)$ & 0.511 \\
\hline Hyperlipidaemia & 13.60 (-13.88 to 41.08$)$ & 0.331 & & & & & & \\
\hline Past or current smokers & 49.39 (-67.71 to 166.48$)$ & 0.401 & & & & & & \\
\hline BMI & $-1.14(-5.07$ to 2.79$)$ & 0.569 & & & & & & \\
\hline \multicolumn{9}{|l|}{ Medications } \\
\hline Beta-blocker & $22.17(-5.02$ to 49.36$)$ & 0.110 & $-0.90(-27.55$ to 25.75$)$ & 0.95 & 0.29 (-27.35 to 27.92$)$ & 0.984 & $-17.61(-130.81$ to 95.60$)$ & 0.757 \\
\hline ACEI/ARB & 19.31 (-29.41 to 68.03) & 0.436 & & & & & & \\
\hline Statin & $6.17(-20.43$ to 32.76$)$ & 0.649 & & & & & & \\
\hline Dietary energy intake & $0.003(-0.015$ to 0.020$)$ & 0.769 & & & & & & \\
\hline Saturated fatty acid & $-2.31(-4.84$ to 0.22$)$ & 0.074 & $-0.58(-3.03$ to 1.87$)$ & 0.643 & $0.47(-2.42$ to 3.35$)$ & 0.750 & $-3.39(-8.07$ to 1.28$)$ & 0.151 \\
\hline PUFA & -2.12 (-6.71 to 2.47$)$ & 0.364 & & & & & & \\
\hline MUFA & $-4.97(-2.33$ to 1.33$)$ & 0.594 & & & & & & \\
\hline Fiber & $-0.103(-2.28$ to 2.07$)$ & 0.926 & & & & & & \\
\hline $\mathrm{CVD}_{\text {/risk equivalent }}{ }^{3}$ & $22.68(-9.90$ to 55.26$)$ & 0.172 & $-51.81(-90.32$ to -13.30$)$ & $0.008^{*}$ & - & - & - & - \\
\hline $\begin{array}{l}\text { High carbohydrate } \\
\text { diet }(\geqq 60 \%)\end{array}$ & $50.52(-6.03$ to 107.07$)$ & 0.080 & $52.46(-3.09$ to 108.01$)$ & 0.064 & $\begin{array}{c}73.50 \text { (10.81 to } 136.19) \text { Full Model Estimate } 2 \text { : } \\
231.39 \text { (87.19 to } 375.58)\end{array}$ & $0.022^{*} 0.003^{*}$ & $-28.52(-147.83$ to 90.80$)$ & 0.634 \\
\hline
\end{tabular}

Cl, confidence interval; CVD, cardiovascular disease; BMI, body-mass index; ACEI, angiotensin-converting enzyme inhibitor; ARB, angiotensin receptor blocker; PUFA, polyunsaturated fatty acid; MUFA monounsaturated fatty acid; PWV, pulse wave velocity.

${ }^{1}$ Multivariate Model, adjusted for potential confounders with $p$-value $<0.20$ based on univariate analysis.

${ }^{2}$ Full Model - Entered and adjusted for all independent variables.

${ }^{3} \mathrm{CVD} /$ Risk Equivalent - included coronary artery disease, ischemic stroke, and type II diabetes mellitus without prior coronary artery disease/ischemic stroke.

${ }^{*} \mathrm{p}$-value $<0.05$. 
validated in our study. Also, the small sample size of the patient sample $(\mathrm{n}=364)$ and the control sample $(\mathrm{n}=93)$, and the small number of subjects with low carbohydrate intake, also limits the conclusions draw from the multivariate analysis as well as the statistical power of the study. Future large randomized controlled studies will be important to confirm the causality by investigating the potentially protective effects of reduced carbohydrate intake against atherosclerotic progression in patients with high risk of cardiovascular events.

\section{Conclusions}

High habitual carbohydrate intake is associated with increased arterial stiffness in patients with established cardiovascular disease or risk equivalent.

\section{Competing interests}

The authors declare that they have no competing interests.

\section{Authors' contributions}

HTC performed the data collection and analysis, drafted the manuscript, and revised it critically for important intellectual content; YHC, KHY, and CPL participated in study design and execution, drafted the manuscript and revised it critically for important intellectual content; SWL participated in study design, data collection and site management; ST performed the biochemical measurements; HFT supervised the overall vascular function study design and direction, data collection and critical analysis, and writing/revision of manuscript. All authors read and approved the final manuscript.

\section{Acknowledgements}

This study was supported by CRCG Small Project Funding of University of Hong Kong (Project No. 200907176063) and the Sun Chieh Yeh Heart Foundation.

\section{Author details}

'Division of Cardiology, Department of Medicine, Queen Mary Hospital, the University of Hong Kong, Hong Kong, China. ${ }^{2}$ Department of Medicine, Tung Wah Hospital, Hong Kong, China. ${ }^{3}$ Department of Clinical Biochemistry Unit, Queen Mary Hospital, Hong Kong, China.

Received: 30 October 2012 Accepted: 5 February 2014

Published: 21 February 2014

\section{References}

1. Miller ER 3rd, Erlinger TP, Appel LJ: The effects of macronutrients on blood pressure and lipids: an overview of the DASH and OmniHeart trials. Curr Atheroscler Rep 2006, 8(6):460-465.

2. Charlton KE, Wolmarans $P$, Marais AD, Lombard CJ: Macronutrient intake and cardiovascular risk factors in older coloured South Africans. East Afr Med J 1997, 74(8):478-486.

3. Appel LJ, Moore TJ, Obarzanek E, Vollmer WM, Svetkey LP, Sacks FM, Bray GA, Vogt TM, Cutler JA, Windhauser MM, Lin PH, Karanja N: A clinical trial of the effects of dietary patterns on blood pressure. DASH Collaborative Research Group. N Engl J Med 1997, 336(16):1117-1124.

4. Swain JF, McCarron PB, Hamilton EF, Sacks FM, Appel LJ: Characteristics of the diet patterns tested in the optimal macronutrient intake trial to prevent heart disease (OmniHeart): options for a heart-healthy diet. J Am Diet Assoc 2008, 108(2):257-265

5. McLaughlin T, Carter S, Lamendola C, Abbasi F, Yee G, Schaaf P, Basina M, Reaven G: Effects of moderate variations in macronutrient composition on weight loss and reduction in cardiovascular disease risk in obese, insulinresistant adults. Am J Clin Nutr 2006, 84(4):813-821.

6. Appel LJ, Sacks FM, Carey VJ, Obarzanek E, Swain JF, Miller ER 3rd, Conlin PR, Erlinger TP, Rosner BA, Laranjo NM, Charleston J, McCarron P, Bishop LM, OmniHeart Collaborative Research Group: Effects of protein, monounsaturated fat, and carbohydrate intake on blood pressure and serum lipids: results of the OmniHeart randomized trial. JAMA 2005, 294 (19):2455-2464.

7. Dzau VJ, Antman EM, Black HR, Hayes DL, Manson JE, Plutzky J, Popma JJ, Stevenson W: The cardiovascular disease continuum validated: clinical evidence of improved patient outcomes: part II: clinical trial evidence (acute coronary syndromes through renal disease) and future directions. Circulation 2006, 114(25):2871-2891.

8. Lavi T, Karasik A, Koren-Morag N, Kanety H, Feinberg MS, Shechter M: The acute effect of various glycemic index dietary carbohydrates on endothelial function in nondiabetic overweight and obese subjects. J Am Coll Cardiol 2009, 53(24):2283-2287.

9. Philippou E, Bovill-Taylor C, Rajkumar C, Vampa ML, Ntatsaki E, Brynes AE, Hickson M, Frost GS: The effect of a 6-month dietary glycemic index manipulation in addition to healthy eating advice and weight loss on arterial compliance and 24-hour ambulatory blood pressure in men: a pilot study. Metabolism 2009, 58(12):1703-1708

10. Alberti KG, Zimmet PZ: Definition, diagnosis and classification of diabetes mellitus and its complications. Part 1: diagnosis and classification of diabetes mellitus provisional report of a WHO consultation. Diabet Med 1998, 15(7):539-553.

11. Wong CY, Qiuwaxi J, Chen H, Li SW, Chan HT, Tam S, Shu XO, Lau CP, Kwong YL, Tse HF: Daily intake of thiamine correlates with the circulating level of endothelial progenitor cells and the endothelial function in patients with type II diabetes. Mol Nutr Food Res 2008, 52(12):1421-1427.

12. Shu XO, Yang G, Jin F, Liu D, Kushi L, Wen W, Gao YT, Zheng W: Validity and reproducibility of the food frequency questionnaire used in the Shanghai Women's Health Study. Eur J Clin Nutr 2004, 58(1):17-23.

13. Chan YH, Lau KK, Yiu KH, Li SW, Chan HT, Tam S, Shu XO, Lau CP, Tse HF: Isoflavone intake in persons at high risk of cardiovascular events: implications for vascular endothelial function and the carotid atherosclerotic burden. Am J Clin Nutr 2007, 86(4):938-945.

14. Chinese Nutrition Society: Daily recommended intake for Chinese. In Press of Tibet People; 2007:200-205.

15. Guerin AP, Blacher J, Pannier B: Impact of aortic stiffness attenuation on survival of patients in end-stage renal failure. Circulation 2001, 103(7):987-992.

16. Ferrier KE, MuhImann MH, Baguet JP: Intensive cholesterol reduction lowers blood pressure and large artery stiffness in isolated systolic hypertension. J Am Coll Cardiol 2002, 39(6):1020-1025.

17. Lasker DA, Evans EM, Layman DK: Moderate carbohydrate, moderate protein weight loss diet reduces cardiovascular disease risk compared to high carbohydrate, low protein diet in obese adults: a randomized clinical trial. Nutr Metab (Lond) 2008, 5:30

18. Park SH, Lee KS, Park HY: Dietary carbohydrate intake is associated with cardiovascular disease risk in Korean: analysis of the third Korea National Health and Nutrition Examination Survey (KNHANES III). Int J Cardiol 2010, 138(3):234-240.

19. Brand-Miller J, Dickinson S, Barclay A, Celermajer D: The glycemic index and cardiovascular disease risk. Curr Atheroscler Rep 2007, 9(6):479-485.

20. Van Popele NMM-RF, Vliegenthart R, Grobbee DE, Asmar R, van der Kuip DA Hofman A, De Feijter PJ, Oudkerk M, Witteman JC: Aortic stiffness is associated with atherosclerosis of the coronary arteries in older adults: the Rotterdam Study. J Hypertens 2006, 24(12):23731-23736

21. Newman AB SD, Manolio TA, Polak J, Fried LP, Borhani NO, Wolfson SK: Ankle-arm index as a marker of atherosclerosis in the Cardiovascular Health Study. Cardiovascular Heart Study (CHS) Collaborative Research Group. Circulation 1993, 88(3):837-845.

22. Willum-Hansen T, Staessen JA, Torp-Pedersen C, Rasmussen S, Thijs L, Ibsen $\mathrm{H}$, et al: Prognostic value of aortic pulse wave velocity as index of arterial stiffness in the general population. Circulation 2006, 113(5):664-670.

23. Eckel RH, Wassef M, Chait A, Sobel B, Barrett E, King G, Lopes-Virella M, Reusch J, Ruderman N, Steiner G, Vlassara H: Prevention conference VI: diabetes and cardiovascular disease: writing group II: pathogenesis of atherosclerosis in diabetes. Circulation 2002, 105:138-143.

24. Wildman RP, Farhat GN, Patel AS, Mackey RH, Brockwell S, Thompson T, SuttonTyrrell $K$ : Weight change is associated with change in arterial stiffness among healthy young adults. Hypertension 2005, 45:187-192. 
25. Tanaka H, Safar ME: Influence of lifestyle modification on arterial stiffness and wave reflections. Am J Hypertens 2005, 18:137-144.

26. Ambrose JA, Barua RS: The pathophysiology of cigarette smoking and cardiovascular disease: an update. J Am Coll Cardiol 2004, 43(10):1731-1737.

27. Schaefer EJ, Gleason JA, Dansinger ML: The effects of low-fat high-carbohydrate diets on plasma lipoproteins, weight loss, and heart disease risk reduction. Curr Atheroscler Rep 2005, 7(6):421-427.

doi:10.1186/1471-2261-14-24

Cite this article as: Chan et al:: Worsened arterial stiffness in high-risk cardiovascular patients with high habitual carbohydrate intake: a cross-sectional vascular function study. BMC Cardiovascular Disorders 2014 14:24

\section{Submit your next manuscript to BioMed Central and take full advantage of:}

- Convenient online submission

- Thorough peer review

- No space constraints or color figure charges

- Immediate publication on acceptance

- Inclusion in PubMed, CAS, Scopus and Google Scholar

- Research which is freely available for redistribution 